\title{
Tumor-targeting novel manganese complex induces ROS-mediated apoptotic and autophagic cancer cell death
}

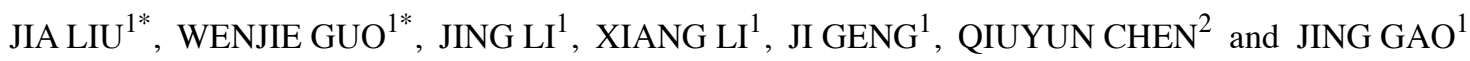 \\ ${ }^{1}$ School of Pharmacy and ${ }^{2}$ School of Chemistry and Chemical Engineering, \\ Jiangsu University, Zhenjiang, Jiangsu 212013, P.R. China
}

Received August 28, 2014; Accepted December 24, 2014

DOI: $10.3892 / \mathrm{ijmm} .2015 .2073$

\begin{abstract}
In this study, the antitumor activity of the novel manganese (II) compound, Adpa-Mn $\left\{\left[(\right.\right.$ Adpa $\left.) \mathrm{Mn}(\mathrm{Cl})\left(\mathrm{H}_{2} \mathrm{O}\right)\right]$ (Adpa=bis(2-pyridylmethyl)amino-2-propionic acid)\}, and its possible mechanisms of action were investigated. In vitro, the growth inhibitory effects of Adpa-Mn (with $\mathrm{IC}_{50}$ values lower than $15 \mu \mathrm{M}$ ) on tumor cell lines were examined by MTT assay. We found that this compound was more selective against cancer cells than the popular chemotherapeutic reagent, cisplatin. We then found that Adpa-Mn achieved its selectivity against cancer cells through the transferrin (Tf)-transferrin receptor (TfR) system, which is highly expressed in tumor cells. Furthermore, Adpa-Mn induced both apoptosis and autophagy, as indicated by chromatin condensation, the activation of poly(ADP-ribose) polymerase (PARP), Annexin V/propidium iodide staining, an enhanced fluorescence intensity of monodansylcadaverine (MDC), as well as the elevated expression of the autophagy-related protein, microtubule-associated protein 1 light chain 3 (LC3). In addition, Adpa-Mn induced the generation of intracellular reactive oxygen species (ROS) and its anticancer effects were significantly reduced following pre-treatment with the antioxidant, $\mathrm{N}$-acetyl cysteine, indicating that ROS triggered cell death. In vivo, the induction of apoptosis and autophagy in tumor tissue was confirmed following treatment with Adpa-Mn, which contributed to its significant antitumor activity against hepatocellular carcinoma (Hep-A cell) xenografts at $10 \mathrm{mg} / \mathrm{kg}$. Taken together, these data suggest the possible use of Adpa-Mn as a novel anticancer drug.
\end{abstract}

\section{Introduction}

Metal ions are required for a number of critical functions in living organisms and are becoming increasingly important as

Correspondence to: Professor Jing Gao, School of Pharmacy, Jiangsu University, 301 Xuefu Road, Zhenjiang, Jiangsu 212013, P.R. China

E-mail: jinggao@ujs.edu.cn

*Contributed equally

Key words: manganese complex, anticancer, autophagy, apoptosis, reactive oxygen species diagnostic and therapeutic tools in the study and and treatment of a variety of human diseases $(1,2)$. Since the success of cisplatin, increasing attention has been paid to metal complexes, which has been one of the most rapidly developing areas of anticancer drugs (3-9). It has been demonstrated that a number of bioinorganic complexes contain metals, such as iron ( $\mathrm{Fe})$, ruthenium $(\mathrm{Ru})$ and can trigger reactive oxygen species (ROS)mediated cell death (10).

Manganese (Mn) is a widely distributed metal which is a required co-factor for many ubiquitous enzymes (11). It has been proven that $\mathrm{Mn}(\mathrm{II})$ ions are mainly absorbed and transported by the transferrin (Tf)-transferrin receptor (TfR) system $(12,13)$. Studies have also demonstrated that TfR is highly expressed in some types of tumor tissue (14-16). To date, simple Mn(II) salts have been reported to exert anti-proliferate effects on several cancer cell lines $(17,18)$ and $\mathrm{Mn}$ (II) complexes containing thiosemicarbazone or hydrazone groups have been reported as antitumor agents (19), generally by the induction of apoptotic cell death at rather high concentrations (in the mM range). Based on these data, we designed and synthesized Mn(II)-containing compounds, in an aim to develop novel tumor-targeting lead chemotherapeutic agents. During our research, a novel Mn(II) complex was synthesized and characterized, and its anticancer activity was previously investigated in a previous study of ours (20); however, its mechanisms of action remain unclear.

Of note, the majority antitumor therapies, including chemotherapy primarily act by inducing apoptosis (type I programmed cell death) in cancer cells; thus, defects in the apoptotic programs may cause resistance to the therapeutic agents $(21,22)$. Thus, an alternative cell death pathway termed autophagic cell death (type II programmed cell death) has emerged as an important mechanism of cancer cell death induced by chemotherapeutic agents (type II programmed cell death) $(10,23,24)$. Autophagy can act as a pro-death mechanism which leads to the destruction of cancer cells, since autophagy is a 'self-cannibalistic' process. There is evidence that autophagy is required for the death of cancer cells with defects in apoptosis $(25,26)$. Moreover, new insights into the molecular mechanisms of autophagy are now leading to the discovery of exciting new potential drug targets (27) and researchers have pointed out that apoptosis and autophagy are tightly connected and may be regulated by the same trigger, such as $\operatorname{ROS}(28,29)$.

In the present study, we demonstrate that the novel manganese (II) compound, Adpa-Mn $\left\{\left[(\right.\right.$ Adpa $\left.) \mathrm{Mn}(\mathrm{Cl})\left(\mathrm{H}_{2} \mathrm{O}\right)\right]$ 
(Adpa=bis(2-pyridylmethyl)amino-2-propionic acid)\}, is a promising new anticancer agent which exerts potent selective activity against a wide range of tumor cell lines in vitro and a carcinoma xenograft model in vivo. Moreover, our results verify that Adpa-Mn causes both apoptotic and autophagic cancer cell death through the induction of ROS generation.

\section{Materials and methods}

Materials. The compound, Adpa-Mn, was synthesized by Professor Chen Qiuyun. Cyclophosphamide (CTX) was produced by Jiangsu Hengrui Medicine Co., Ltd. (Jiangsu, China). 3-(4,5-Dimethyl-2-thiazolyl)-2,5-diphenyl$2 \mathrm{H}$-tetrazolium bromide (MTT) was purchased from Amresco LLC (Solon, OH, USA) and Annexin V/PI kits for the detection of apoptosis were from Life Technologies (Carlsbad, CA, USA). Culture medium (DMEM/1640), trypsin and EDTA-2.Na were purchased from Thermo Fisher Scientific (Waltham, MA, USA). Fetal bovine serum was obtained from Sijiqing Biological Engineering Materials (Hangzhou, China). The 2',7' dichlorofluorescin diacetate (DCFH-DA) kit was purchased from the Beyotime Institute of Biotechnology (Nantong, China). Antibodies against microtubule-associated protein 1 light chain 3 (LC3; 2775), poly(ADP-ribose) polymerase (PARP; 9542), autophagy-related protein (ATG)7 (2631) and ATG siRNA (6604) were obtained from Cell Signaling Technology (Boston, MA, USA); $\beta$-actin (sc-8423), GAPDH (sc-25778), cytochrome $c$ (sc-13561), COX IV (sc-376731), tubulin (sc-5546), TfR1 (sc-9099) and caspase-3 (sc-98785) were from Santa Cruz Biotechnology, Inc. (Santa Cruz, CA, USA). 3-Methyladenine (3-MA), N-acetyl cysteine (NAC), chloroquine (CQ), cisplatin, ferric citrate and deferoxamine (DFO) were purchased from Sigma-Aldrich. Wortmanin was purchased from Beyotime. All other chemicals were of high purity and were from commercial sources.

Cell culture. The human cancer cell lines, including HeLa (cervical adenocarcinoma), HepG2 (hepatocellular carcinoma), A549 (lung adenocarcinoma), MCF-7 (breast cancer), U251 (glioblastoma), LoVo (colon cancer), A875 (melanoma) and ECA-109 (human esophageal squamous carcinoma) cells, as well as the human normal liver cell line, WRL-68 (immortalized), were obtained from the Cancer Cell Repository (Shanghai Cell Bank, Shanghai, China). The cells were maintained in DMEM medium supplemented with $10 \%(\mathrm{v} / \mathrm{v})$ heat-inactivated fetal bovine serum, antibiotics $(100 \mathrm{U} / \mathrm{ml}$ penicillin and $100 \mathrm{U} / \mathrm{ml}$ streptomycin), at $37^{\circ} \mathrm{C}$ in a humidified atmosphere of $5 \% \mathrm{CO}_{2}$ (Thermo Fisher Scientific).

Animals. Female imprinting control region (ICR) mice (6-8 weeks old) were purchased from the Comparative Medicine Research Center of Yangzhou University [Yangzhou, China, register no: SCXK (JIANGSU) 2007-0001]. The mice were maintained on a standard diet and water was made freely available.

Ethics statement. Animal welfare and experimental procedures were carried out strictly in accordance with the Guide for the Care and Use of Laboratory Animals (The Ministry of Science and Technology of China, 2006) and the related ethical regulations of our university. All efforts were made to minimize the suffering of the animals and to reduce the number of animals used.

Histological analysis. For histological morphometry, tumor tissues were fixed with $10 \%$ formalin and embedded in paraffin, and cut into 5- $\mu \mathrm{m}$-thick sections and stained with hematoxylin and eosin (H\&E; Nanjing Jiancheng Technology Co., Nanjing, China).

Cell viability assay. The cells were plated at a density of approximately $4 \times 10^{3}$ viable cells per well in 96-well plates. Various concentrations of the compound were used to treat the cells in triplicate. Following incubation for the indicated periods of time, MTT assay was performed to measure cell viability using a 96-well plate reader (Spectra Max 190; Molecular Devices Corp., Sunnyvale, CA, USA).

Cell morphological changes observed under a Nikon TE2000 microscope. The morphological changes of the $\mathrm{H}_{2} \mathrm{~B}$-GFPlabeled HeLa cells (stable cell line) were observed under a Nikon TE2000 microscope (Nikon, Tokyo, Japan) with a live cell system (LCS) which can provide $\mathrm{CO}_{2}$, temperature control and position fixing. The $\mathrm{H}_{2} \mathrm{~B}-\mathrm{GFP}-\mathrm{labeled} \mathrm{HepG} 2$ cells, which were incubated with $20 \mu \mathrm{M}$ Adpa-Mn, were observed for $24 \mathrm{~h}$. The bright and fluorescence imaginations of the cells were recorded and analyzed.

Cell apoptosis assay. The cells were stained with Annexin V/PI at room temperature for $15 \mathrm{~min}$ in the dark and then analyzed using a FACSCalibur flow cytometer (Becton-Dickinson, Franklin Lakes, NJ, USA). Annexin $\mathrm{V}^{+} / \mathrm{PI}^{-}$and Annexin $\mathrm{V}^{+} / \mathrm{PI}^{+}$cells were considered as apoptotic cells in the early and late phase.

Visualization of monodansylcadaverine (MDC)-labeled vacuoles. Autophagic vacuoles were labeled with MDC by incubating the HepG2 cells which were grown on coverslips with $0.05 \mathrm{mM}$ MDC in PBS at $37^{\circ} \mathrm{C}$ for $10 \mathrm{~min}$. The cellular fluorescent changes were observed under a fluorescence microscope (Nikon; excitation, 380 to $420 \mathrm{~nm}$; emission, $450 \mathrm{~nm}$; Nikon).

GFP-LC3 plasmid transfection. The HepG2 cells transfected with green fluorescent protein (GFP)-LC3-expressing plasmid were treated with Adpa-Mn, and the fluorescence of GFP-LC3 was viewed under a fluorescence microscope (Nikon).

Western blot analysis. Proteins were extracted in lysis buffer (30 mM Tris, pH 7.5, $150 \mathrm{mM}$ sodium chloride, $1 \mathrm{mM}$ phenylmethanesulfonyl fluoride, $1 \mathrm{mM}$ sodium orthovanadate, $1 \%$ Nonidet P-40, $10 \%$ glycerol, and phosphatase and protease inhibitors), separated by SDS-PAGE and electrophcoretically transferred onto polyvinylidene fluoride membranes. The membranes were probed with antibodies (LC3, PARP, ATG7 and $\beta$-actin) overnight at $4^{\circ} \mathrm{C}$, and then incubated with a horse radish peroxidase-coupled secondary antibody. Detection was performed using a LumiGLO chemiluminescent substrate system [Kirkegaard \& Perry Laboratories, Inc. (KPL), Gaithersburg, MD, USA].

Mitochondrial membrane potential assay. Changes in mitochondrial membrane potential were measured using JC-1 staining. 
A

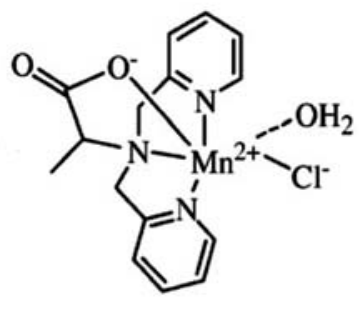

B
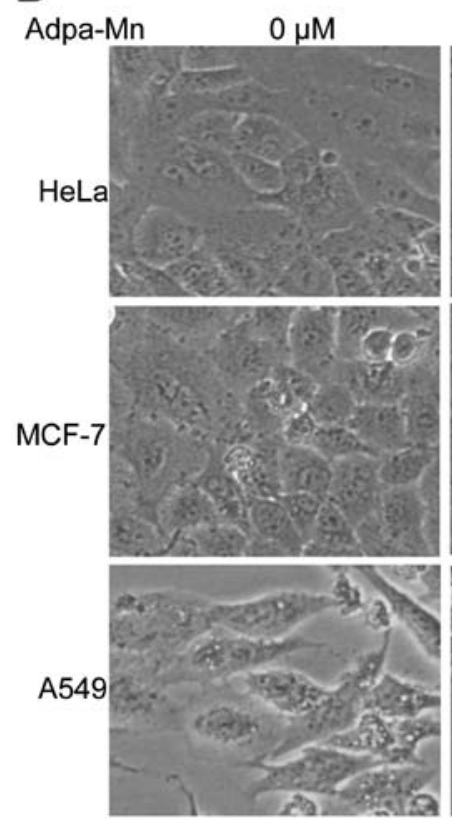

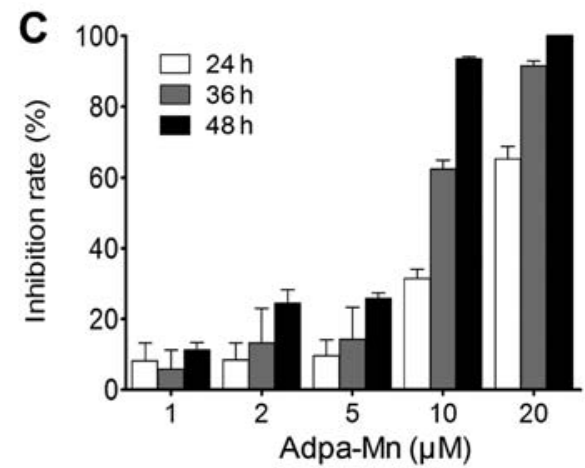

$10 \mu \mathrm{M}$
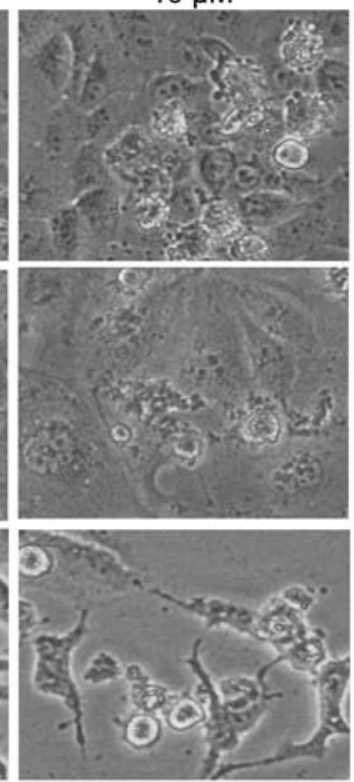
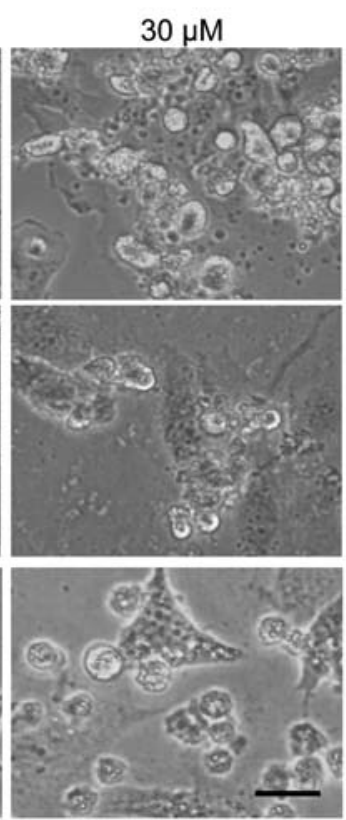

Figure 1. Adpa-Mn significantly inhibits the proliferation of various types of human cancer cells. (A) Structure of Adpa-Man. HepG2 cells were exposed to various concentrations of Adpa-Mn. (B) The morphological changes (cell body shrinkage and cell number reduction) of the cells were photographed. (C) Cell proliferation was determined by MTT assay every $12 \mathrm{~h}$. Data represent the means \pm SD of 3 different experiments.

Briefly, following treatment, the HepG2 cells were washed with PBS and incubated with $5 \mu \mathrm{g} / \mathrm{ml} \mathrm{JC}-1$ at $37^{\circ} \mathrm{C}$ for $30 \mathrm{~min}$. The cells were then washed twice with PBS and immediately assessed by fluorescence spectrometry (Spectra MaxGemini; Molecular Devices Corp.). A $488 \mathrm{~nm}$ filter was used for the excitation of JC-1. Emission filters of 535 and $595 \mathrm{~nm}$ were used to quantify the population of mitochondria with green (JC-1 monomers) and red (JC-1 aggregates) fluorescence. The ratio of red/green was used to reflect the mitochondrial membrane potential.

Measurement of intracellular ROS production. The intracellular generation of ROS was analyzed using the probe, DCFH-DA. Cells were incubated with $10 \mu \mathrm{M}$ DCFH-DA at $37^{\circ} \mathrm{C}$ for $15 \mathrm{~min}$. The DCF fluorescence distribution of $1 \times 10^{4}$ cells was tehn measured by fluorescence spectrometry (Spectra MaxGemini; Molecular Devices Corp.) at an excitation wavelength of $488 \mathrm{~nm}$ and at an emission wavelength of $535 \mathrm{~nm}$.

Evaluation of the antitumor effects of Adpa-Mn in vivo. Mouse hepatocellular carcinoma (Hep-A; $1 \times 10^{7}$ ) cells (grown in donor mice) were transplanted subcutaneously into the armpits of the ICR mice. One day following transplantion, the mice were randomly allocated to either the control (vehicle control, received
PBS) or treatment groups, with 10 mice in each group. The drugs (Adpa-Mn and CTX) were administered intraperitoneally on days 0-9. All efforts were made to minimize the suffering of the animals and to reduce the number of animals used and the mice were sacrificed by cervical dislocation. After the mice were sacrificed, the solid tumors were separated. Tumor weights were measured and the tumor growth inhibition ratio was calculated. The toxic effects of Adpa-Mn on the spleen were also observed.

Statistical analysis. Comparisons were made by one-way analysis of variance (ANOVA). Differences were considered statistically significant when $\mathrm{p}<0.05$. All experiments were repeated at least 3 times. All graphs were created using GraphPad Prism 5 software.

\section{Results}

Adpa-Mn exerts inhibitory effects on various types of cancer cells. First we examined the cytotoxic effects of Adpa-Mn (chemical structure shown in Fig. 1A) on various types of human cancer cells, including human cervical cancer cells (HeLa), human hepatocellular carcinoma cells (HepG2), human lung cancer cells (A549), human breast cancer cells (MCF-7), human 

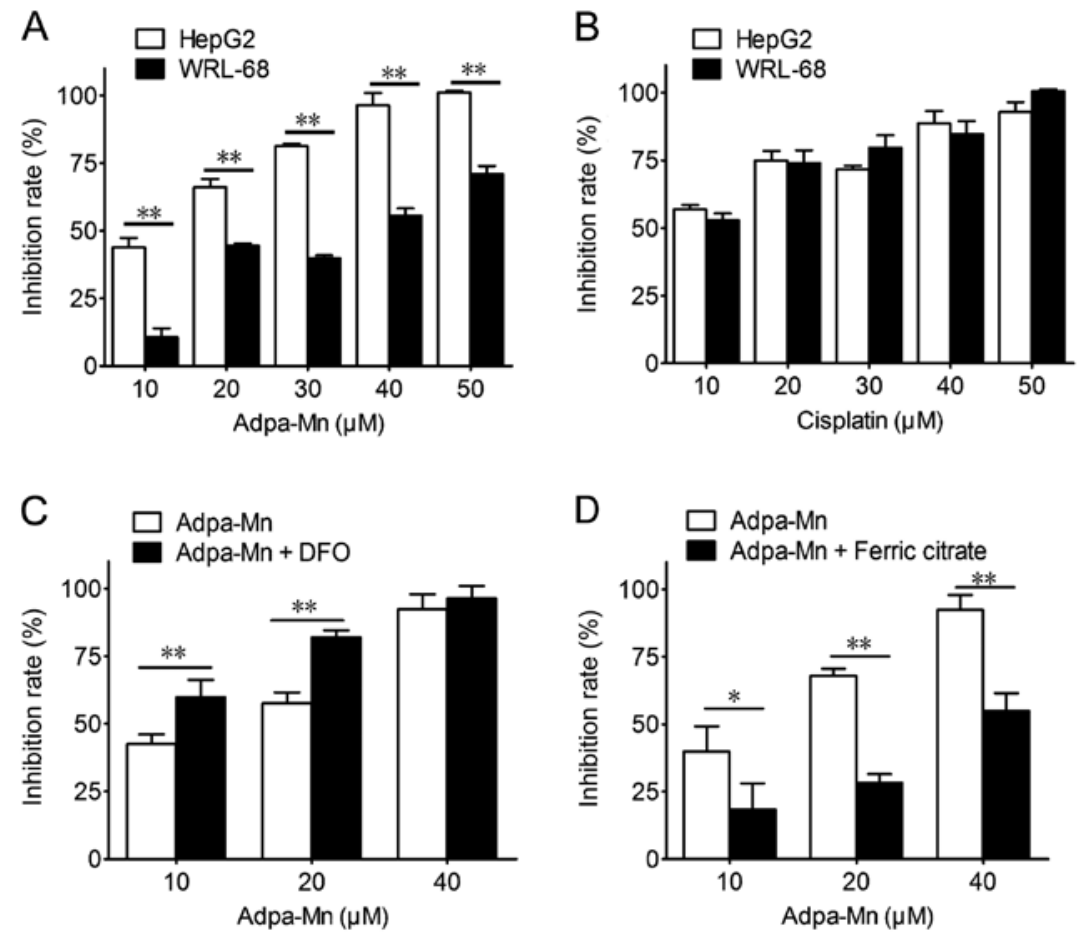

E

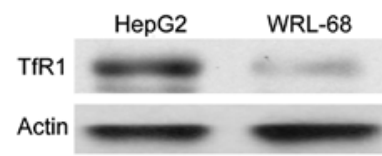

Figure 2. Adpa-Mn exhibits selective inhibition on cancer cell proliferation through the transferrin/transferrin receptor (Tf-1/TfR-1) system. HepG2 cells and WRL-68 cells were treated with various concentrations of (A) Adpa-Mn or (B) cisplatin for $24 \mathrm{~h}$ and cell viability was detected by MTT assay. HepG2 cells were pre-treated with deferoxamine (DFO; $10 \mu \mathrm{M})(\mathrm{C})$ or ferric citrate $(100 \mu \mathrm{M})(\mathrm{D})$ for $24 \mathrm{~h}$, then treated with various concentrations of Adpa-Mn for $24 \mathrm{~h}$. (E) The expression of TfR-1 in HepG2 and WRL-68 cells. Data represent the means \pm SEM of 3 different experiments. " $p<0.05$ and ${ }^{* *} \mathrm{p}<0.01$ vs. the respective control.

Table I. Half maximal inhibitory concentration $\left(\mathrm{IC}_{50}\right)$ of Adpa-Mn in various cancer cell lines.

\begin{tabular}{lc}
\hline Cell line & $\mathrm{IC}_{50}(\mathrm{M})$ \\
\hline HeLa & $12.3 \pm 1.5$ \\
HepG2 & $10.8 \pm 0.9$ \\
A549 & $14.2 \pm 0.5$ \\
MCF-7 & $6.5 \pm 0.7$ \\
U251 & $9.1 \pm 0.6$ \\
LoVo & $10.2 \pm 0.4$ \\
A875 & $18.6 \pm 0.3$ \\
ECA-109 & $16.2 \pm 0.3$
\end{tabular}

glioblastoma cells (U251), human colon cancer cells (LoVo), human melanoma cells (A875) and human esophageal squamous carcinoma cells (ECA-109). The morphological changes (cell body shrinkage and cell number reduction) of the cells were photographed (Fig. 1B) and the 50\% inhibitory concentration $\left(\mathrm{IC}_{50}\right.$ ) was calculated (Table I). Our results revealed that Adpa-Mn exerted a significant cytotoxic effect with an $\mathrm{IC}_{50}$ between 5 and $20 \mu \mathrm{M}$. Furthermore, we demonstrated that Adpa-Mn inhibited HepG2 cell proliferation not only in a dose-dependent manner, but also in a time-dependent manner (Fig. 1C).
Adpa-Mn selectively kills cancer cells through the Tf-TfR system. The selectivity of Adpa-Mn on cancer cells was examined. Adpa-Mn demonstrated significant selectivity towards the liver cancer cells (HepG2) compared with the non-malignant liver epithelial cells (WRL-68) (Fig. 2A), and compared to treatment with cisplatin (Fig. 2B). The preferential toxicities toward the cancer cells compared to the non-cancer cells suggest the possibile use of this compound as an antitumor agent. Due to the high expression level of TfR in the tumor cells, the selectivity of Adpa-Mn may be due to its transport mechanisms. As shown in Fig. 2E, the expression of TfR1 in the HepG2 cells was higher than that in the WRL-68 cells. As shown in Fig. 2C and D, pre-treatment with ferric citrate reduced the inhibitory effects of Adpa-Mn on the growth of HepG2 cells, while pre-treatment with deferoxamine (DFO) promoted them.

Adpa-Mn induces apoptotic cell death through the mitochondrial pathway. We then wished to determine which cell death pathway was employed when the cells were treated with Adpa-Mn. The possibility of apoptosis was investigated. As shown in Fig. 3A, following incubation with Adpa-Mn for $12 \mathrm{~h}$, cell shrinkage and chromatin condensation were observed. As the inubation time increased, the nuclei became condensed and had divided into several parts; apoptotic bodies had emerged, and an increasing number of cells began to exhibit these characteristics. We calculated the percentage of 
A
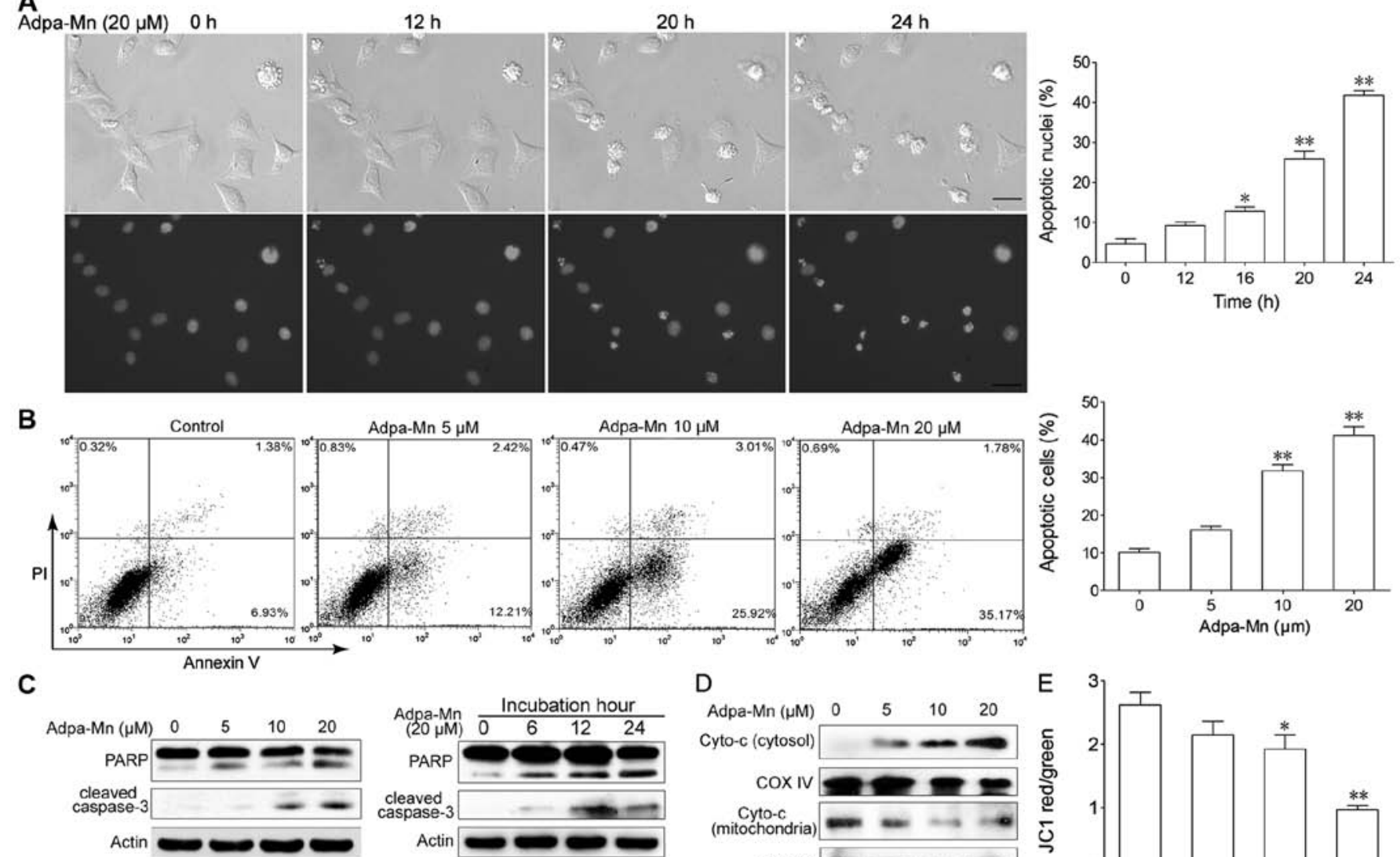

Adpa-Mn $5 \mu \mathrm{M}$
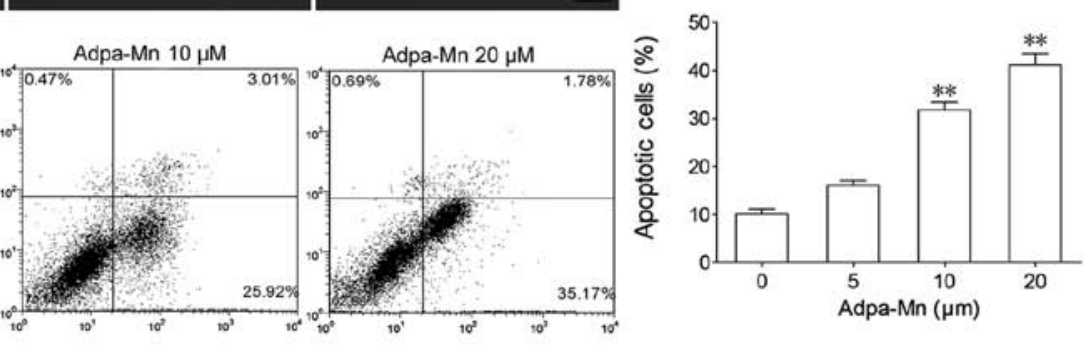

C
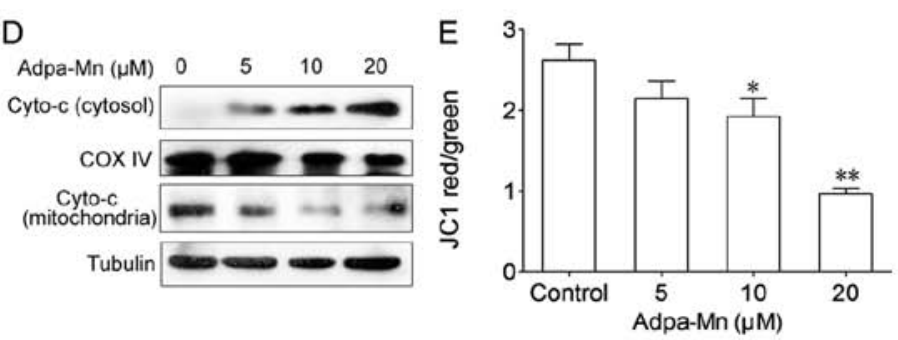

Figure 3. (Adpa-Mn induces apoptotic cell death. (A) $\mathrm{H}_{2} \mathrm{~B}$-GFP-labeled HeLa cells (stable cell line) were treated with Adpa-Man (20 $\mu \mathrm{M}$ ) for $24 \mathrm{~h}$, morphology and nuclei were photographed using a Nikon TE2000 microscope with a live cell system. Apoptotic nuclei were counted in 10 fields of vision at each time point and the apoptotic percentage was calculated. Scale bar, $5 \mu \mathrm{m}$. (B) HepG2 cells treated with Adpa-Mn were collected and subjected to Annexin V/propidium iodide (PI) staining. (C) PARP and caspase-3 activation were assessed by western blot analysis. (D) The release level of cytochrome $c$ from the mitochondria was examined by western blot analyiss. (E) HepG2 cells treated with Adpa-Mn were collected and subjected to mitochondrial membrane potential analysis. Data represent the means \pm SD of 3 different experiments. ${ }^{*} \mathrm{p}<0.05$ and ${ }^{* *} \mathrm{p}<0.01$, as compared with the untreated (control) group.

cells which showed these characteristics and found that this percentage increased in a time-dependent manner (Fig. 3A). FACS analyses revealed that the number of Annexin $\mathrm{V}^{+} / \mathrm{PI}^{-}$ cells had increased from 6.9 to $25.9 \%(10 \mu \mathrm{M})$ and from $35.2 \%$ $(20 \mu \mathrm{M})$ following treatment with Adpa-Mn (Fig. 3B). Western blot analysis revealed that Adpa-Mn triggered the activation of PARP and the cleavage of caspase-3 (Fig. 3C) in a dose- and time-dependent manner.

To further examine the pathway of apoptosis, we monitored the changes in apoptotic molecules related to the mitochondrial pathway in the HepG2 cells. As shown in Fig. 3D and E, treatment with Adpa-Mn disrupted the mitochondrial transmembrane potential and with the collapse of the mitochondrial transmembrane potential, the release of cytochrome $c$ from the mitochondrion to the cytosol was greatly increased in a dose-dependent manner (Fig. 3C). These results indicate that the mitochondrial apoptotic pathway is involved in the Adpa-Mn-induced apoptosis of cancer cells.

Adpa-Mn induces autophagic cell death. We also wished to determine whether autophagic cell death contributes to the cytotoxic effects of Adpa-Mn. The possibility of the induction of autophagy was analyzed by autophagic vacuole organelle (AVO) formation, the formation of GFP-LC3 vacuoles and LC3 conversion. AVO formation was detected and measured by staining with MDC, as previously described (30). The Adpa-Mn-treated HepG2 cells showed a greater fluorescence intensity and a greater number of MDC-labeled particles compared with the control (untreated) group (Fig. 4A), indicating that Adpa-Mn increased MDC recruitment to autophagosomes in the cytoplasm which was suppressed by the autophagy inhibitor, 3-MA (Fig. 4A).

Conversion of LC3-I (19 $\mathrm{kDa})$ to the pre-autophagosomal and autophagosomal membrane-bound form of LC3-II $(17 \mathrm{kDa})$ is another specific marker of autophagosome formation (31). GFP-fused LC3 was transfected into the cells to detect autophagy. As shown in Fig. 4B, the formation of GFP-LC3-labeled vacuoles in the HepG2 cells was markedly increased $12 \mathrm{~h}$ following treatment with $20 \mu \mathrm{M}$ Adpa-Mn. The formation of these vacuoles was inhibited by treatment with 3-MA, a specific inhibitor of the autophagic process during the early stages (Fig. 4A). Consistent with the above results, 

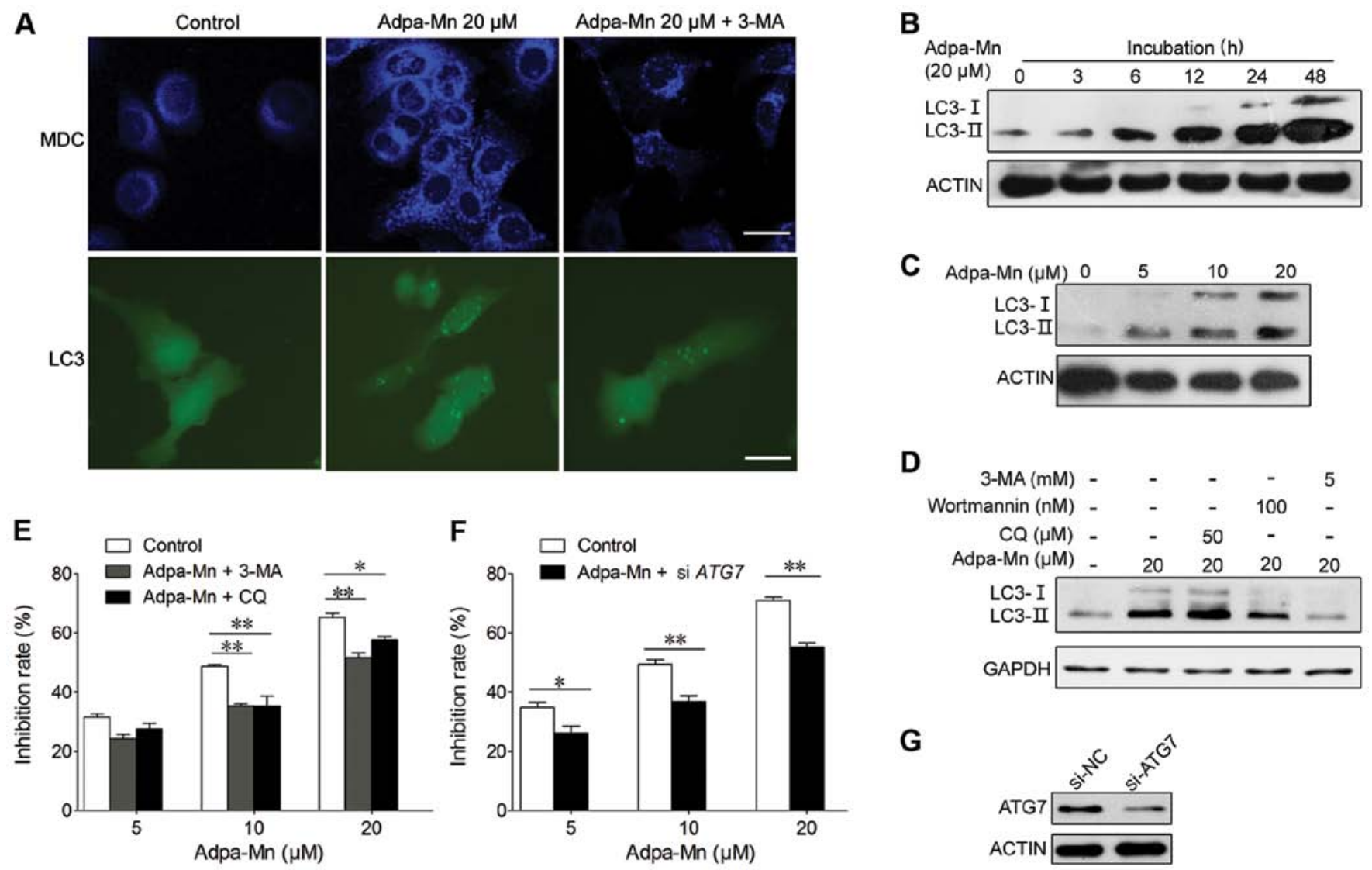

G

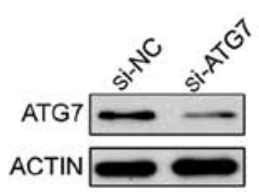

Figure 4. Adpa-Mn induces autophagic cell death. (A) HepG2 cells transfected with GFP-LC3 cDNA were treated with $20 \mu \mathrm{M}$ Adpa-Mn for $12 \mathrm{~h}$ with or without pre-treatment with $5 \mathrm{mM} 3$-methyladenine (3-MA) for $2 \mathrm{~h}$. The formation of vacuoles containing GFP-LC3 (dots) was examined by fluorescence microscopy. In another set of experiments, HepG2 cells were treated with $20 \mu \mathrm{M}$ Adpa-Mn for $12 \mathrm{~h}$ with or without pre-treatment with $5 \mathrm{mM} 3$-MA for $2 \mathrm{~h}$ and then incubated with $0.05 \mathrm{mM}$ monodansylcadaverine (MDC) for $10 \mathrm{~min}$. The cells were then analyzed by fluorescence microscopy. Scale bar, $5 \mu \mathrm{m}$. Protein expression of LC3 in (B-D) was determined by western blot analysis. (B) HepG2 cells were cultured with $20 \mu \mathrm{M}$ Adpa-Mn for 3, 6, 12, 24 and 48 h. (C) HepG2 cells were cultured with the indicated concentrations of Adpa-Mn for $24 \mathrm{~h}$. (D) HepG2 cells were treated with $20 \mu \mathrm{M}$ Adpa-Mn for $24 \mathrm{~h}$ with or without 3-MA, wartmanin and chloroquine (CQ) pre-treatment for $2 \mathrm{~h}$. (E) HepG2 cells were treated with $20 \mu \mathrm{M}$ Adpa-Mn for $24 \mathrm{~h}$ with or without 3-MA, and CQ pre-treatment for $2 \mathrm{~h}$. MTT assay was used to evaluate the cell death rate. (F) HepG2 cells were transfected with control siRNA or siRNA targeting autophagy-related gene (ATG7). After $48 \mathrm{~h}$, the cells were treated with $0,5,10$ or $20 \mu \mathrm{M}$ Adpa-Mn for $24 \mathrm{~h}$, and cell death was measured by MTT assay. (G) The knockdown of ATG7 was confirmed by western blot analysis. Data represent the means \pm SEM of 3 different experiments. ${ }^{*} \mathrm{p}<0.05$ and $^{* *} \mathrm{p}<0.01$ vs. respective control.

the LC3-I to LC3-II conversion markedly increased with the increasing incubation time or the increasing dose of Adpa-Mn in the HepG2 cells, as shown by western blot analysis (Fig. 4B and $C$ ); this was also inhibited by treatment with the autophagy inhibitors, wortmanin and 3-MA (Fig. 4D).

To determine whether autophagy is associated with the cell death induced by Adpa-Mn in the HepG2 cells, we examined whether the inhibition of autophagy using autophagy inhibitors or by silencing autophagy-related genes affects cell death in the HepG2 cells. First, using MTT assay, we found that pre-treatment with the autophagy inhibitor, 3-MA, or the autophagolysosome fusion inhibitor, CQ, significantly inhibited Adpa-Mn-induced cell death in a dose-dependent manner (Fig. 4E). Second, we also found that silencing autophagy-related genes (ATG7) using siRNA significantly reduced the cell death induced by Adpa-Mn (Fig. 4F and G). These results suggest that autophagy contributes to the death of HepG2 cells treated with Adpa-Mn.

ROS generation triggered by Adpa-Mn is indispensable for the induction of apoptosis and autophagy. To determine whether ROS play an important role in the cell death induced by Adpa-Mn, the intracellular ROS levels were measured by fluorescence spectrometry after the cells were labeled with DCFH-DA. As shown in Fig. 5A, treatment with $20 \mu \mathrm{M}$ of Adpa-Mn for $6 \mathrm{~h}$ led to an increase in ROS generation in the HepG2 cells. The generation of ROS significantly increased, as detected by the higher fluorescence intensity compared to the control (untreated) group. The generation of ROS increased in a dose- and time-dependent manner, suggesting that the continuous generation of ROS is involved in the whole process of Adpa-Mn-induced cell death (Fig. 5A). To determine the role of ROS in the Adpa-Mn-induced cell death, we examined whether the inhibition of ROS by NAC affects apoptosis or autophagy in HepG2 cells. As shown in Fig. 5B, pre-treatment with NAC effectively suppressed the generation of ROS. MTT assay revealed that the cell death induced by Adpa-Mn was markedly reduced by NAC (Fig. 5C). Annexin V/PI staining also revealed that pre-treatment with NAC inhibited the apoptosis induced by Adpa-Mn (Fig. 5D). At the same time, the Adpa-Mn-induced MDC-labeled particle formation and LC3 conversion were inhibited by NAC (Fig. 5E and F). These 
A

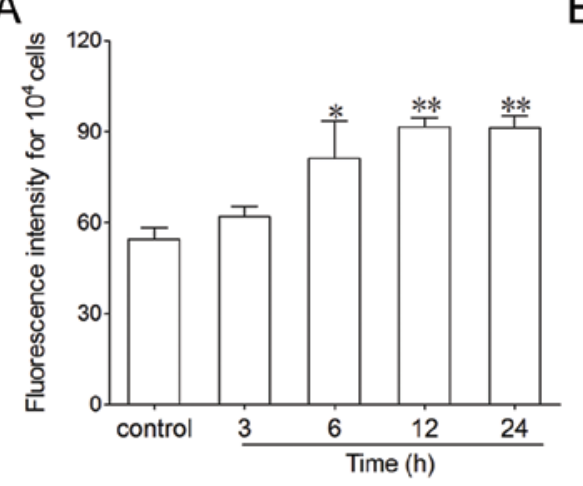

B

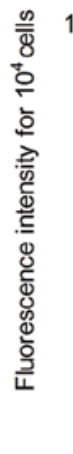

C

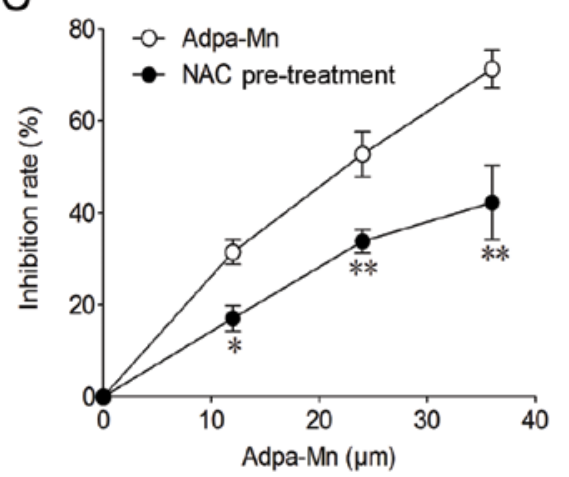

D
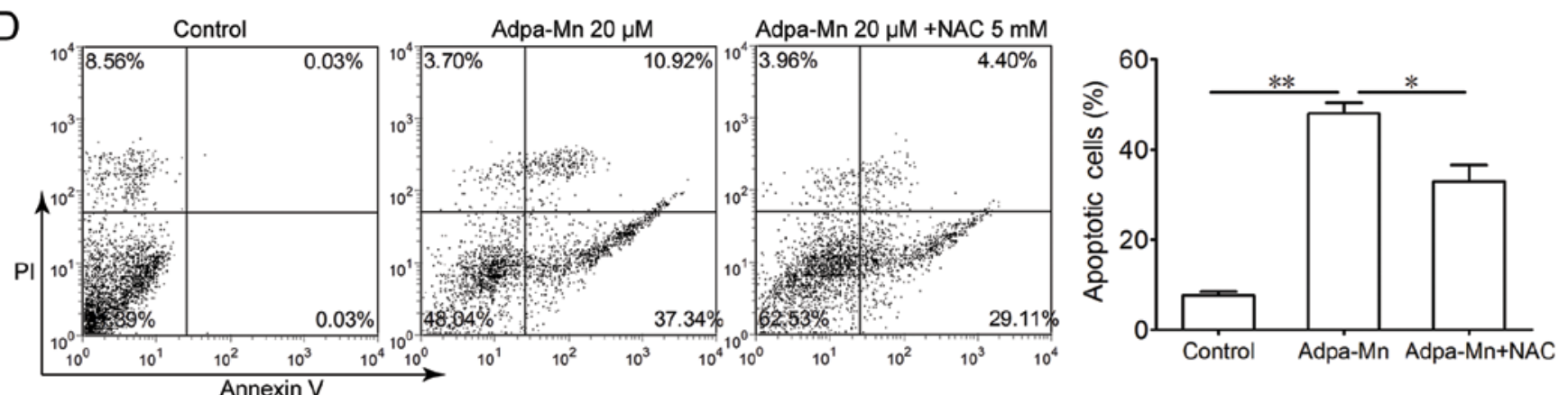

E
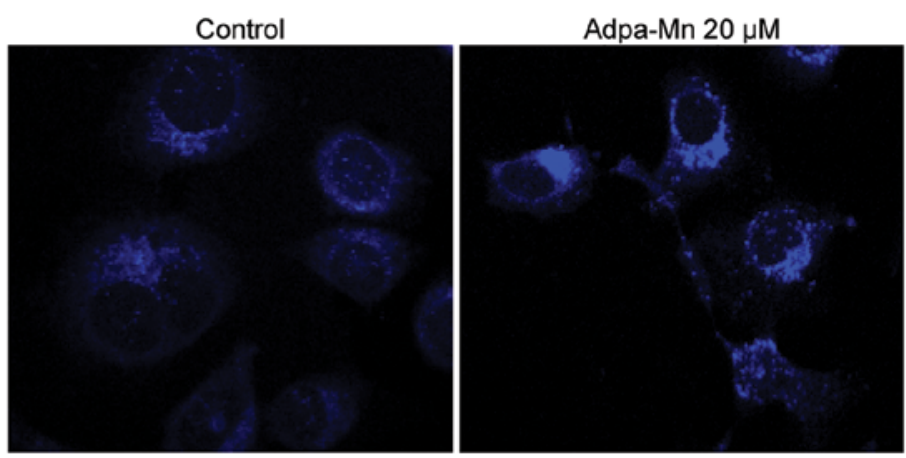

Adpa-Mn $20 \mu \mathrm{M}+\mathrm{NAC} 5 \mathrm{mM}$

$\mathrm{F}$

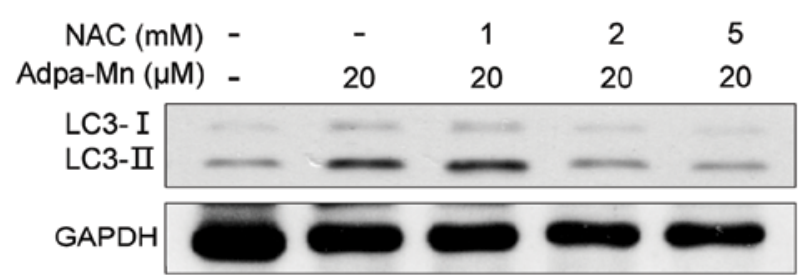

Figure 5. Adpa-Mn induces apoptotic and autophagic cell death dependent on reactive oxygen species (ROS) generation. (A) HepG2 cells were exposed to $20 \mu \mathrm{M}$ Adpa-Mn for different periods of time and ROS generation was detected by DCFH-DA. (B) HepG2 cells were exposed to $5,10,20 \mu \mathrm{M}$ Adpa-Mn for $12 \mathrm{~h}$ with or without NAC pre-treatment for $2 \mathrm{~h}$ and ROS generation was detected by DCFH-DA. (C) HepG2 cells were exposed to 5, 10, 20 $\mu \mathrm{M}$ Adpa-Mn for $24 \mathrm{~h}$ with or without NAC pre-treatment for $2 \mathrm{~h}$ and cell death was examined by MTT assay. (D) HepG2 cells were exposed to $20 \mu \mathrm{M}$ Adpa-Mn for $24 \mathrm{~h}$ with or without NAC pre-treatment for $2 \mathrm{~h}$ and apoptosis was evaluated by Annexin V/ propidium iodide (PI) staining. (E and F) HepG2 cells were exposed to $20 \mu \mathrm{M}$ Adpa-Mn for $12 \mathrm{~h}$ with or without NAC pre-treatment for $2 \mathrm{~h}$ and autophagic vacuole organelle (AVO) formation and LC 3 expression were evaluated by western blot analysis. Scale bar, $5 \mu \mathrm{m}$.

results demonstrate that ROS are necessary for the Adpa-Mninduced apoptotic and autophagic death of HepG2 cells.

In vivo anticancer activity of Adpa-Mn against a mouse hepatocellular carcinoma xenograft. To examine the antitumor activity of Adpa-Mn in vivo, we developed a mouse xenograft model of Hep-A cells in ICR mice. The administration of Adpa-Mn (1, 5, $10 \mathrm{mg} / \mathrm{kg}$, once a day) inhibited tumor growth in the mice in a dose-dependent manner (Fig. 6A and B). The tumor inhibition rate at the dose of $10 \mathrm{mg} / \mathrm{kg}$ was $60 \%$, which is comparable to that of $20 \mathrm{mg} \mathrm{kg} \mathrm{CTX,} \mathrm{and} \mathrm{H \& E} \mathrm{staining}$ revealed evident cell death in the tumor tissue (Fig. 6E). Treatment with CTX significantly reduced the body weight and splenic index in the mice, whereas no significant changes were observed in the Adpa-Mn-treated mice (Fig. 6C and D). According to the results in vitro, both PARP and caspase-3 activation and LC3 conversion in the tumor tissue from mice were significantly enhanced following treatment with 

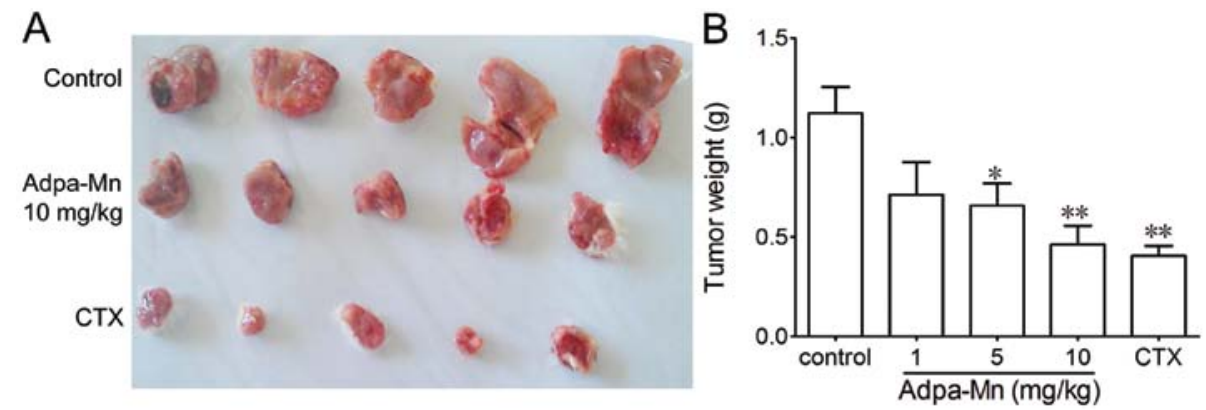

C
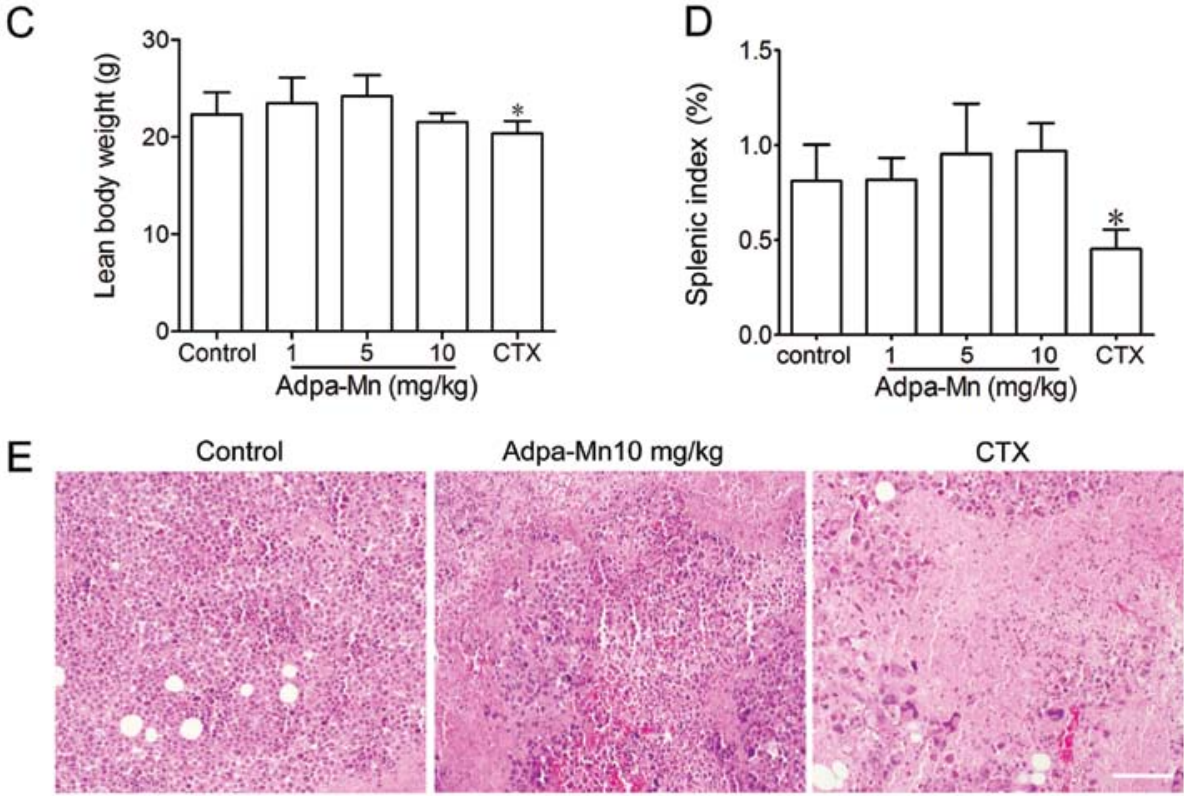

$\mathrm{F}$

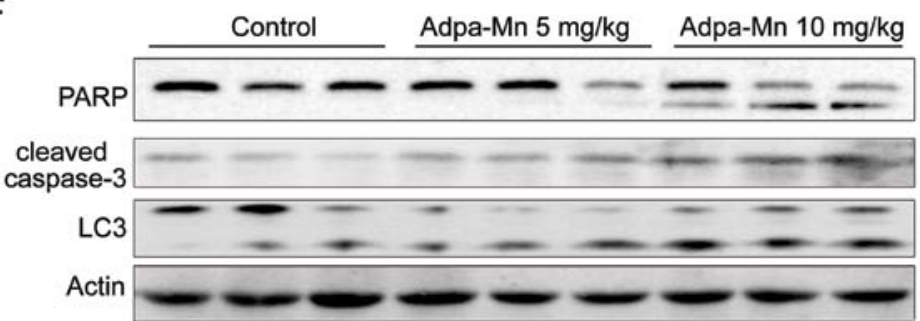

Figure 6. Adpa-Mn inhibits tumor growth in vivo. Hepatocellular carcinoma (Hep-A) 1x107 tumor cells (grown in donor mice) were transplanted subcutaneously into the armpits of ICR mice. One day after transplantion, the mice were randomly allocated to either the control or treatment groups, with 10 mice in each group. Drugs were administered intraperitoneally on days 0-9. After the mice were sacrificed, solid tumors were separated. (A and B) Tumors were photographed and weighed. (C and D) Lean body weight and thymus splenic index were calculated. (E) Paraffin-embedded sections of tumor tissues from mice were analyzed by H\&E staining. Scale bar, $50 \mu \mathrm{m}$. (F) Protein from tumor tissue from mice in each group was extracted and analyzed by western blot analysis. Data represent the means \pm SEM. $n=10,{ }^{*} \mathrm{p}<0.05$ and ${ }^{* *} \mathrm{p}<0.01$ vs. control.

Adpa-Mn, which proved that apoptosis and autophagy were induced (Fig. 6F). These results indicated that Adpa-Mn effectively suppressed tumor growth in vivo, while no significant side-effects were observed.

\section{Disscusion}

The success of cisplatin in the treatment of cancer patients suggests that other metal complexes may also be potential drugs in future chemotherapy regimens. In this study, experiments were performed to verify whether the designed manganese compound, Adpa-Mn, can be used as an anticancer lead compound. In vitro, Adpa-Mn was demonstrated to be active against various types of tumor cells in a dose- and time-dependent manner. In vivo, the growth of mouse hepatocellular carcinoma tumor xenografts was significantly attenuated by Adpa-Mn, which was comparable to the effect of CTX.

The anticancer activity of $\mathrm{Mn}$ (II) has, however, been distinctly enhanced by combination with diverse ligands, including chrysin $(32,33)$. For most of these compounds, interactions with DNA involving intercalation or coordinative binding have been demonstrated. However, the knowledge of the precise molecular mechanisms underlying their increased cytotoxic activity against cancer cells remains limited. $\mathrm{N}$-allyl di(picolyl)amine (Adpa) has been shown to be active against the proliferation of cancer cells (34), capable of complexing $\mathrm{Cu}(\mathrm{II})$ and inducing cell death by DNA interaction and ROS-mediated autophagy $(35,36)$. 
The majority of metal complexes, such as platinum or copper complexes have shown activity for DNA binding and cleavage and the ability to induce cell cycle arrest and apoptosis (36-39). In a previous study of ours, we found that the Adpa-Mn complex exhibited high toxicity against cancer cell lines, but showed weak DNA binding and cleavage activity (34). In agreement with the study that manganese can induce apoptosis in neuronal cells (40), in this study, treatment with Adpa-Mn induced apoptosis, as indicated by nuclei condensation and the appearance of apoptotic bodies, which occurred through the mitochondrial pathway (Fig. 3).

Usually, apoptosis is the major mechanism which destroys cancer cells. A number of chemotherapeutic agents have been designed to kill cancer cells through the induction of apoptosis (41). For example, cisplatin has been reported to induce apoptosis in various types of human tumor cells (42). However, as is known, the decreased effects of anticancer drugs or resistance to apoptosis are becoming a major concern with the long-term use of chemotherapeutic agents. Thus, an alternative form of programmed cell death known as autophagy is becoming increasingly important in cancer therapy $(24,43,44)$. Previously, autophagy was referred to as a physiological process that plays a protective role as cells encounter environmental stresses, such as starvation and pathogen infection (45). It was also classified as type II programmed cell death or autophagic cell death (46). Excessive autophagy can also act as a pro-death mechanism. Rapamycin and its analogs, which induce autophagic cell death by inhibiting mTOR, have been demonstrated to be a potent therapeutic strategy for many tumor types in preclinical clinical studies (47). In this study, we demonstrated that Adpa-Mn induced autophagy, which indeed contributed to its cell death-inducing mechanisms (Fig. 4). The following characteristics of autophagy were observed in the present study: the formation of AVO and the punctate distribution of LC3 and the elevated ratio of LC3-II to LC3-I. Furthermore, we confirmed that the Adpa-Mn-induced cell death was mediated through autophagy: cell death was significantly suppressed by the inhibition of autophagy, by pre-treatment of the cells with various autophagy inhibitors or the transfection of siRNA targeting ATG7 (Fig. 4).

It is well established that mitochondria and ROS play a central role in the process of cell death, including apoptosis and autophagy (48-53). It has been suggested that the mitochondria can regulate the release of proteins inducing apoptosis and autophagy through the excessive generation of ROS and the self-directed induction of mitochondrial permeability transition (MPT), while ROS play several roles in cellular processes, including DNA damage, mitochondrial dysfunction, the activation of signaling pathways and the activation of transcription factors, leading to the upregulation of genes (54). Consistent with these observations, in this study, Adpa-Mn induced mitochondrial dysfunction, including the collpase of mitochondrial membrane potential following the accumulation of ROS. When ROS were scavenged, both the Adpa-Mn-induced autophagy and apoptosis were hampered (Fig. 5) which proved that ROS generation triggered by Adpa-Mn was responsible for the apoptotic and autophagic cell death. However, the association between the apoptosis and autophagy induced by Adpa-Mn warrant further investigations, which may provide some strategies for the regulation of apoptosis/autophagy and drug design.
Taken together, our findings suggest that Adpa-Mn exhibits potent and stable anti-proliferative and cytotoxic activity against diverse tumor types in vitro, as well as against tumor xenografts mediated by the ROS-dependent apoptotic and autophagic cell death. Our study thus provides useful insight into the investigation of apoptosis and autophagy in cancer cells and offers a rationale for the development of complexes as effective chemotherapeutic agents against human cancer in clinical settings.

\section{Acknowledgements}

This study was supported by grants from the National Natural Science Foundation of China (no. 21271090), the Natural Science Foundation of Jiangsu Province (no. BK2012710), Jiangsu University (no. 13JDG064) and the Graduate Research and Innovation Projects in Jiangsu Province (no. 1293000504). We would also like ot thank Professor Qin Zhenghong for providing the GFP-LC3 expression vector and Professor Li Chaojun for providing the $\mathrm{H}_{2} \mathrm{~B}-\mathrm{GFP}$-labeled HeLa cell line.

\section{References}

1. Guo $\mathrm{Z}$ and Sadler PJ: Metals in Medicine. Angew Chem Int Ed 38: 1512-1531, 1999.

2. Orvig $\mathrm{C}$ and Abrams MJ: Medicinal inorganic chemistry: introduction. Chem Rev 99: 2201-2204, 1999.

3. Hartinger CG, Nazarov AA, Ashraf SM, Dyson PJ and Keppler BK: Carbohydrate-metal complexes and their potential as anticancer agents. Curr Med Chem 15: 2574-2591, 2008.

4. Chen D, Milacic V, Frezza M and Dou QP: Metal complexes, their cellular targets and potential for cancer therapy. Curr Pharm Des 15: 777-791, 2009.

5. Marzano C, Pellei M, Tisato F and Santini C: Copper complexes as anticancer agents. Anticancer Agents Med Chem 9: 185-211, 2009.

6. Ott I: On the medicinal chemistry of gold complexes as anti cancer drugs. Coord Chem Rev 253: 1670-1681, 2009.

7. Timerbaev AR: Advances in developing tris(8-quinolinolato) gallium(iii) as an anticancer drug: critical appraisal and prospects. Metallomics 1: 193-198, 2009.

8. Kostova I: Titanium and vanadium complexes as anticancer agents. Anticancer Agents in Med Chem 9: 827-842, 2009.

9. Zhang CX and Lippard SJ: New metal complexes as potential therapeutics. Curr Opin Chem Biol 7: 481-489, 2003.

10. Rafique S, Idrees M, Nasim A, Akbar H and Athar A: Transition metal complexes as potential therapeutic agents. Biotech Mol Biol Rev 5: 38-45, 2010.

11. Wedler FC: Biological significance of manganese in mammalian systems. In: Progress in Medicinal Chemistry. Ellis GP and Luscombe DK (eds). Elsevier, Cardiff, pp89-133, 1993.

12. Aschner M, Guilarte TR, Schneider JS and Zheng W: Manganese: recent advances in understanding its transport and neurotoxicity. Toxicol and Appl Pharmacol 221: 131-147, 2007.

13. Au C, Benedetto A and Aschner M: Manganese transport in eukaryotes: the role of DMT1. Neurotoxicology 29: 569-576, 2008.

14. Calzolari A, Oliviero I, Deaglio S, et al: Transferrin receptor 2 is frequently expressed in human cancer cell lines. Blood Cells Mol Dis 39: 82-91, 2007.

15. Sciot R, Paterson AC, van Eyken P, Callea F, Kew MC and Desmet VJ: Transferrin receptor expression in human hepatocellular carcinoma: an immunohistochemical study of 34 cases. Histopathology 12: 53-63, 1988.

16. Sciot R, Van Eyken P and Desmet VJ: Transferrin receptor expression in benign tumours and in hepatoblastoma of the liver. Histopathology 16: 59-62, 1990.

17. El Mchichi B, Hadji A, Vazquez A and Leca G: p38 MAPK and MSK1 mediate caspase- 8 activation in manganese-induced mitochondria-dependent cell death. Cell Death and Differ 14: 1826-1836, 2007.

18. Oubrahim H, Stadtman ER and Chock PB: Mitochondria play no roles in Mn(II)-induced apoptosis in HeLa cells. Proc Natl Acad Sci USA 98: 9505-9510, 2001. 
19. Kovala-Demertzi D, Hadjipavlou-Litina D, Staninska M, Primikiri A, Kotoglou C and Demertzis MA: Anti-oxidant, in vitro, in vivo anti-inflammatory activity and antiproliferative activity of mefenamic acid and its metal complexes with manganese(II), cobalt(II), nickel(II), copper(II) and zinc(II). J Enzym Inhib Med Chem 24: 742-752, 2009.

20. Qiu-Yun C, Dong-Fang Z, Juan H, Wen-Jie G and Jing G: Synthesis, anticancer activities, interaction with DNA and mitochondria of manganese complexes. J Inorg Biochem 11: 1141-1417, 2010.

21. Amaravadi RK, Lippincott-Schwartz J, Yin XM, et al: Principles and current strategies for targeting autophagy for cancer treatment. Clin Cancer Res 17: 654-666, 2011.

22. Liu EY and Ryan KM: Autophagy and cancer - issues we need to digest. J Cell Sci 125: 2349-2358, 2012.

23. Shen HM and Codogno P: Autophagic cell death: Loch Ness monster or endangered species? Autophagy 7: 457-465, 2011.

24. Kondo Y and Kondo S: Autophagy and cancer therapy. Autophagy 2: 85-90, 2006.

25. Mujumdar N and Saluja AK: Autophagy in pancreatic cancer: an emerging mechanism of cell death. Autophagy 6: 997-998, 2010.

26. Yu L, Alva A, Su H, et al: Regulation of an ATG7-beclin 1 program of autophagic cell death by caspase-8. Science 304 1500-1502, 2004.

27. Rubinsztein DC, Gestwicki JE, Murphy LO and Klionsky DJ: Potential therapeutic applications of autophagy. Nat Rev Drug Discov 6: 304-312, 2007.

28. Liu B, Cheng Y, Zhang B, Bian HJ and Bao JK: Polygonatum cyrtonema lectin induces apoptosis and autophagy in human melanoma A375 cells through a mitochondria-mediated ROS-p38-p53 pathway. Cancer letters 275: 54-60, 2009.

29. Ghavami S, Eshragi M, Ande SR, et al: S100A8/A9 induces autophagy and apoptosis via ROS-mediated cross-talk between mitochondria and lysosomes that involves BNIP3. Cell Res 20: 314-331, 2010.

30. Biederbick A, Kern HF and Elsässer HP: Monodansylcadaverine (MDC) is a specific in vivo marker for autophagic vacuoles. Eur J Cell Biol 66: 3-14, 1995.

31. Klionsky DJ, Abeliovich H, Agostinis P, et al: Guidelines for the use and interpretation of assays for monitoring autophagy in higher eukaryotes. Autophagy 4: 151-175, 2008.

32. Ansari KI, Grant JD, Kasiri S, Woldemariam G, Shrestha B and Mandal SS: Manganese(III)-salens induce tumor selective apoptosis in human cells. J Inorg Biochem 103: 818-826, 2009.

33. Hille A, Ott I, Kitanovic A, et al: [N,N'-Bis(salicylidene)-1,2phenylenediamine]metal complexes with cell death promoting properties. J Biol Inorg Chem 14: 711-725, 2009.

34. Chen QY, Huang J, Li JF and Gao J: Synthesis, interaction with mitochondrial and cancer cells of a dinuclear manganese(II) complex: $\mathrm{Mn}_{2}(\mathrm{Adpa})_{2} \mathrm{Cl}_{4}$. Chinese J Inorg Chem 24: 1789-1793, 2008 (In Chinese)

35. Guo WJ, Ye SS, Cao N, Huang J, Gao J and Chen QY: ROS-mediated autophagy was involved in cancer cell death induced by novel copper(II) complex. Exp Toxicol Pathol 62: 577-582, 2010

36. Chen QY, Huang J, Guo WJ and Gao J: Synthesis, characterization, DNA interaction and cytotoxic activities of copper complexes with ethyl 2-[bis(2-pyridylmethyl)amino]propionate. Spectrochim Acta A Mol Biomol Spectrosc 72: 648-653, 2009.
37. Rajendiran V, Karthik R, Palaniandavar M, et al: Mixed-ligand copper(II)-phenolate complexes: effect of coligand on enhanced DNA and protein binding, DNA cleavage, and anticancer activity. Inorg Chem 46: 8208-8221, 2007.

38. Selvakumar B, Rajendiran V, Uma Maheswari P, Stoeckli-Evans $\mathrm{H}$ and Palaniandavar M: Structures, spectra, and DNA-binding properties of mixed ligand copper(II) complexes of iminodiacetic acid: The novel role of diimine co-ligands on DNA conformation and hydrolytic and oxidative double strand DNA cleavage. J Inorg Biochem 100: 316-330, 2006.

39. Dhar S, Nethaji $M$ and Chakravarty AR: DNA cleavage on photoexposure at the d-d band in ternary copper(II) complexes using red-light laser. Inorg Chem 45: 11043-11050, 2006.

40. Shibata S, Maeda M, Furuta K, et al: Neuroprotective effects of (arylthio)cyclopentenone derivatives on manganese-induced apoptosis in PC12 cells. Brain Res 1294: 218-225, 2009.

41. Sun SY, Hail N Jr and Lotan R: Apoptosis as a novel target for cancer chemoprevention. J Natl Cancer Inst 96: 662-672, 2004.

42. Qin LF and Ng IO: Induction of apoptosis by cisplatin and its effect on cell cycle-related proteins and cell cycle changes in hepatoma cells. Cancer Lett 175: 27-38, 2002.

43. Moretti L, Yang ES, Kim KW and Lu B: Autophagy signaling in cancer and its potential as novel target to improve anticancer therapy. Drug Resist Updat 10: 135-143, 2007.

44. Mathew R, Karantza-Wadsworth V and White E: Role of autophagy in cancer. Nat Rev Cancer 7: 961-967, 2007.

45. Klionsky DJ and Emr SD: Autophagy as a regulated pathway of cellular degradation. Science 290: 1717-1721, 2000.

46. Galluzzi L, Maiuri MC, Vitale I, et al: Cell death modalities: classification and pathophysiological implications. Cell Death Differ 14: 1237-1243, 2007.

47. Iwamaru A, Kondo Y, Iwado E, et al: Silencing mammalian target of rapamycin signaling by small interfering RNA enhances rapamycin-induced autophagy in malignant glioma cells. Oncogene 26: 1840-1851, 2006.

48. Zamzami N, Susin SA, Marchetti P, et al: Mitochondrial control of nuclear apoptosis. J Exp Med 183: 1533-1544, 1996.

49. Kroemer G, Galluzzi L and Brenner C: Mitochondrial membrane permeabilization in cell death. Physiol Rev 87: 99-163, 2007.

50. Chen Y, McMillan-Ward E, Kong J, Israels SJ and Gibson SB: Oxidative stress induces autophagic cell death independent of apoptosis in transformed and cancer cells. Cell Death Differ 15: 171-182, 2008.

51. Scherz-Shouval R, Shvets E, Fass E, Shorer H, Gil L and Elazar Z: Reactive oxygen species are essential for autophagy and specifically regulate the activity of Atg4. EMBO J 26: 17491760, 2007.

52. Circu ML and Aw TY: Reactive oxygen species, cellular redox systems, and apoptosis. Free Radic Biol Med 48: 749-762, 2010.

53. Simon HU, Haj-Yehia A and Levi-Schaffer F: Role of reactive oxygen species (ROS) in apoptosis induction. Apoptosis 5: 415-418, 2000

54. Schumacker PT: Reactive oxygen species in cancer cells: live by the sword, die by the sword. Cancer Cell 10: 175-176, 2006. 